\title{
El método ontofenomenológico existencial del estudio de la subjetividad en Jean-Paul Sartre
}

\section{Danila Suárez Tomé}

\author{
Dirección: Dr. Esteban García \\ Jurado: Dra. Alcira Bonilla, Dr. Samuel Cabanchik, Dra. Graciela Ralón \\ Fecha de defensa: 15 de febrero de 2019
}

Jean-Paul Sartre es conocido eminentemente como un pensador de la libertad. La máxima que vociferaba el existencialismo de los años 40, "el hombre está condenado a ser libre", ha sido tal vez el pensamiento más grave del filósofo francés. Y si bien el grueso de su obra escrita está dedicado a intentar dar respuesta al "¿y ahora qué?" que surge de la condena a la libertad y responsabilidad absoluta del existente humano, nuestra tesis doctoral se enfocó en el camino que lo Ilevó hacia dicho pensamiento fundamental, el camino fenomenológico.

El período de la producción sartriana estudiado en nuestra tesis doctoral es el que corresponde a los 13 años que van desde el comienzo de su estancia en el Institut Français de Berlín y la publicación de L'Existentialisme est un humanisme en 1946. Este período abarca las siguientes obras: L'Imagination (1936), La Transcendance de l'Ego (1937), La Nausée (1938), Esquisse d'une théorie des émotions (1939) "Une Idée fondamentale de la phénoménologie de Husserl: L'Intentionnalité" (1939), L'Imaginaire (1949), L'Être et le Néant (1943), Huis clos (1944), L'Existentialisme est un humanisme (1946), "Conscience de soi et connaissance de soi” (1948), la obra publicada póstumamente Cahiers pour une morale (1983) y los Carnets de la drôle de guerre (1983).

El problema general investigado en nuestra tesis fue el acceso descriptivo a la esfera prerreflexiva de la existencia humana, la cual constituye, para Sartre, el estrato más originario de la subjetividad humana, y la posibilidad de su conceptualización filosófica. De acuerdo con Sartre, si quiero realizar una descripción fiel del dominio prerreflexivo de la conciencia, yo debería poder tener un acceso a las vivencias tal cual se presentan, en su espontaneidad, en el cogito prerreflexivo, a condición de que este acceso no sea reflexivo ni motivado. Es en L'Être et le Néant en donde Sartre tematiza los derechos de esta reflexión purificante. Esta forma originaria de la reflexión consiste en la simple presencia del para-sí reflexivo al para-sí reflejo. La reflexión cómplice (la que pone a la conciencia como objeto) no es originaria, sino que se funda sobre la reflexión pura. De esta manera podríamos nosotros aprehender la conciencia en su espontaneidad. El problema es que esta forma de acceso a la conciencia, al quedar despojada de toda motivación, al imprimirle la necesidad de ser un acaecimiento espontáneo, se presenta como un milagro. Es posible, pero de hecho no sucede. $\mathrm{O}$ al menos está investida de cierta complejidad.

Aquí se abre una pregunta esencial que consiste en el problema central de la investigación: en tanto la reflexión pura ofrece un modo de acceso a lo prerreflexivo, pero, tal como está tematizada por Sartre, no puede constituirse en método de análisis fenomenológico del mismo; y siendo que la reflexión cómplice no puede analizar lo prerreflexivo so pena de falsearlo, entonces, ¿qué posibilidad resta para analizar lo prerreflexivo con fidelidad y cómo repercute en la concepción sartriana sobre el método fenomenológico y el desarrollo de la ontología?

La investigación realizada sobre los ensayos tempranos de Jean-Paul Sartre del período que va desde 1933 a 1946, y especialmente sobre su obra central L'Être et le Néant, muestra, en primer lugar, que los temas epistemológicos y metodológicos no han sido un foco de atención primaria en la filosofía de Sartre. Aun cuando abundan reflexiones metodológicas, no existe en el corpus temprano de su producción un segmento dedicado enteramente a la reflexión epistemológica y al establecimiento propositivo de una metodología particular. Lo que se puede extraer de su obra temprana es la idea de que el método fenomenológico sartriano tiende a quedar atascado en una aporía metodológica fruto de críticas que parecieran contraponerse entre sí: la crítica al cogito cartesiano, en tanto él no constituye la dimensión originaria del existente humano por ser egológico y, por lo tanto, derivado de una instancia previa que lo constituye; la crítica a la reflexión fenomenológico-trascendental, invalidada en sus derechos de certeza apodíctica por objetivante; la crítica a la hermenéutica heideggeriana, método que Sartre descarta por evadir el hecho de que toda comprensión es conciencia 
(de) comprensión y, por lo tanto, la conciencia es el dominio relevante a ser analizado en lo que respecta a la existencia humana. Dentro de este cruce de perspectivas, el propósito en nuestra tesis fue el de presentar una exégesis de su obra temprana que permita explicitar de modo sistemático el método ontofenomenológico existencial sartriano, en conjunto con la sistematización correspondiente de la noción de subjetividad. Siguiendo el desarrollo sartriano de la noción de subjetividad a través de toda su obra temprana hasta L'Être et le Néant, resultó posible desvelar de modo más específico y sistemático el método característico del discurrir filosófico sartriano.

En lo que respecta a la noción de subjetividad, se mostró que Sartre opera con una noción que conceptualizamos como "subjetividad no egológica". Esta concepción plantea, en primer lugar, una dessolidarización de las nociones de subjetividad con la noción de psique, ego, egología o personalidad. Esto es, subjetividad no es sinónimo de yo. En segundo lugar, esta noción se presenta como compleja, esto es, constituida por distintos niveles: un nivel cogitativo, en cuyo centro se encuentra la importante noción de autoconciencia prerreflexiva, un nivel ontológico, signado por la estructura de la falta y el deseo de ser, y expresado en el proyecto fundamental, y un nivel existencial, en donde se evidencia la estructura mundana del existente humano como libertad en situación. En tercer lugar, se muestra que estos tres niveles de la subjetividad se condicen los tres niveles del método fenomenológico sartriano, que denominamos "método de ontología fenomenológica existencial" o "método ontofenomenológico existencial". Estos tres términos incluyen las tres perspectivas que anidan en la propuesta filosófica sartriana $y$, tienen un paralelismo claro con los estratos de la subjetividad.
La interpretación propuesta en nuestra tesis del método sartriano se desprende de una lectura conjunta de La transcendance de l'Ego y L'Être et le Néant. En la introducción a L'Être et le Néant, Sartre dice que sólo podemos conceptualizar filosóficamente aqueIlo que podemos describir fenomenológicamente: el fenómeno de ser. Pero el ser del fenómeno, el ser transfenoménico, sólo puede ser experimentado a través de ciertos temples de carácter aperiente como la angustia, el tedio o la náusea. Nuestra propuesta fue interpretar que la reflexión pura, la cual de acuerdo al discurrir teórico sartriano nos garantiza un acceso no distorsionado al ser del fenómeno, no es, de hecho, un acto reflexivo en sentido estricto: $\mathrm{ni}$ natural ni fenomenológico, sino que constituye una experiencia anímica que abre al existente humano, a través de la crisis existencial, a la experiencia del ser y de la nada y a la posibilidad de una reconversión existencial, esto es, un cambio de lo que Sartre denomina el "proyecto fundamental". Ante la imposibilidad de la conceptualización filosófica de esta experiencia, el registro literario de obras como La Nausée o Les Chemins de la liberté, pero también la utilización de un lenguaje literario en L'Être et le Néant, permiten a Sartre dar cuenta de estas experiencias de un modo no conceptual. La reflexión pura, por lo tanto, presenta el primer paso del método sartriano en tanto otorga la base existencial de un segundo paso que se da en L'Être et le Néant, esto es, la reducción óntico-ontológica que consta en la reconducción de las conductas concretas del existente humano a sus condiciones de posibilidad, estas son las estructuras ontológicas de la existencia pasibles de ser descritas, en un tercer momento, por la mirada fenomenológica reflexiva que podrá, entonces, conceptualizar y sistematizar estas estructuras en un discurso filosófico. 